\title{
CONSIDERACIONES JURÍDICAS EN TORNO AL CONCEPTO DE EUTANASIA
}

\author{
Adelio Misseroni Raddatz \\ Abogado \\ Consultor del Programa Regional de Bioética de la Organización \\ Panamericana de la Salud
}

Correspondencia: Nueva de Lyon 96, piso $6^{\circ}$, Providencia, Santiago de Chile

E-mail: amisseroni@invat.cl 
Consideraciones jurídicas en torno al concepto de eutanasia - A. Misseroni 


\title{
CONSIDERACIONES JURÍDICAS EN TORNO AL CONCEPTO DE EUTANASIA
}

\author{
Adelio Misseroni Raddatz
}

\section{Resumen}

Dada la confusión conceptual que existe en relación con la expresión eutanasia, el objetivo de la presente monografía consiste, precisamente, en dilucidar el sentido y alcance de esta expresión desde una perspectiva jurídico-penal, para así poder determinar qué conductas son penalmente relevantes y cuáles deben ser necesariamente excluidas del ámbito del ius puniendi.

Como paso siguiente, el autor analiza los elementos determinantes de las conductas eutanásicas, consideradas siempre desde la perspectiva penal. Una vez precisado el alcance de la expresión, es posible analizar dichas conductas desde el punto de vista de su tipificación objetiva, para revisar, posteriormente, algunas legislaciones latinoamericanas que tipifican expresamente dichas prácticas.

Finalmente, se analizará la factibilidad ética y jurídica de una legislación propiamente eutanásica, a la luz del principio de la dignidad de la persona humana, reconocido-explícita o implícitamente-por los principales instrumentos internacionales y por todas los códigos políticos de los Estados sociales y democráticos de derecho.

Palabras clave: Eutanasia activa, Eutanasia pasiva, Eutanasia de doble efecto, Adistanasia o Antidistanasia, Ortotanasia, Medios proporcionados/desproporcionados, Ensañamiento terapéutico, Paciente terminal, Homicidio por piedad, Dignidad de la persona humana.
Resumo

Dada a confusão conceitual que existe com relação à expressão eutanásia, o objetivo do presente trabalho consiste, precisamente, em elucidar o sentido e alcance da mesma através de uma perspectiva Jurídico-penal. Pretende-se, assim, determinar quais condutas são penalmente relevantes e quais devem ser excluídas do âmbito da ius puniendi.

$\mathrm{Na}$ seqüência, o autor analisa os elementos determinantes das condutas eutanásicas, consideradas sempre sob a perspectiva penal. Uma vez estabelecido o alcance da expressão, torna-se possível analisar as mencionadas condutas do ponto de vista de sua tipificação objetiva, para, posteriormente, revisar brevemente algumas legislações latinoamericanas que as tipificam.

Finalmente, analisa-se a factibilidade ética e jurídica de uma legislação propriamente eutanásica à luz do princípio da dignidade da pessoa humana, reconhecida explícita ou implícitamente pelos principais instrumentos internacionais e por todos os códigos políticos dos Estados sociais e democráticos de direito.

Palavras chaves: Eutanásia ativa, Eutanásia passiva, Eutanásia de duplo efeito, Adistanásia ou Antidistanásia, Ortotanásia, Meios proporcionais/desproporcionais, Encarniçamento terapêutico, Paciente terminal, Homicídio por piedade, Dignidade da pessoa humana. 


\section{Abstract}

Given the conceptual confusion that exists about the term euthanasia, the objective of this monograph consists of elucidating the sense and reach of this expression, from a legal and penal perspective, and by so doing, determine what behaviors are legally relevant and which should be necessarily excluded from the ius poniendi ambit.

As a next step, the author analyses the determining elements of the euthanistic behavior, always considered from a penal perspective.

Once the reach of the expression is determined, it is possible to analyze such behavior from the perspective of its objective classification for an ulterior brief reviewing of some Latin American normatives that clearly typify such behaviors.

Finally, the ethical and legal feasibility of a legislation properly euthanistic will be analysed in the light of the principle of human dignity, explicitly or implicitly recognized by the main international instruments and by all the political codes of the social and democratic States of right.

Key words: Active euthanasia, Passive euthanasia, Double effect euthanasia, Adisthanasia or Anti-disthanasia, Orthotanasia, Proportionate / disproportionate means, Therapeutic rage, Terminally-ill patient, Mercy killing, Human being's dignity.

\section{Résumé}

Compte tenu de la confusion conceptuelle qui existe par rapport à l'expression euthanasie, le but de la monographie en cours consiste, précisément, à élucider le sens et l'envergure de cette expression d'une perspective juridique et pénale, pour ainsi pouvoir déterminer les conduites qui sont pénalement remarquables et celles qui doivent être exclues nécessairement du cadre du ius puniendi.

Comme deuxième démarche, l'auteur analyse les éléments déterminants des conduites authanasiques considérées toujours du point de vue pénal. Après avoir préciser l'ampleur de l'expression, il sera possible de faire l'analyse des conduites mentionnées du point de vue de leurs classification objective pour réviser brièvement, par la suite, quelques législations en Amérique latine qui standarisent expressément telles conduites.

Finalement, il faudra analyser la faisabilité éthique et juridique d'une législation proprement euthanasique, à la lumière du principe de dignité de la personne humaine, reconu -de facon explicite ou implicite- par les princiapales instruments internationaux et par tous les codes politiques des États sociaux et démocratiques de droit.

Mots clés: Euthanasie, Euthanasie Passive, Euthanasie à double effet, Adisthanasie, Orthotanasie, Moyens Proportionnés/Disproportionnés, Ensaignement Thérapeutique, Patient terminal, Homicide par pitié, Dignité de la personne humaine. 


\section{Introducción}

El 28 de noviembre de 2000, la Cámara de Diputados del Parlamento holandés aprobó, por 104 votos a favor y 40 en contra, un proyecto de ley que legaliza la eutanasia y el suicidio asistido. Posteriormente, el día 10 de abril de 2001, el Senado de ese país dio también su aprobación a este proyecto, con 46 votos a favor y 28 en contra. Estas prácticas han sido toleradas durante muchos años en los Países Bajos, pero, hasta ahora, continuaban siendo ilegales, lo que significaba -en teoría- que un médico que realizaba alguna de estas conductas podía ser encausado penalmente.

Con esta ley, Holanda se convierte en el primer país europeo donde es posible para un médico practicar la eutanasia o proporcionar asistencia a un enfermo terminal que decide poner fin a su vida.

La aprobación de este proyecto de ley por parte del país europeo, ha puesto de relieve, una vez más, la discusión sobre las connotaciones éticas de la eutanasia y su eventual despenalización o legalización. Por esta razón, consideramos del todo atingente hacer ciertas precisiones sobre esta materia, con el objeto de esclarecer las confusiones terminológicas que existen al respecto. En efecto, con la expresión eutanasia -por lo menos desde un punto de vista etimológicose hace referencia a una serie de conductas, muchas de las cuales son irreprochables desde un punto de vista ético y totalmente ajustadas a derecho.

Por último, es también del todo relevante que nos preguntemos si una legislación propiamente eutanásica es aceptable desde un punto de vista ético y jurídico, es decir, si es aceptable en un Estado social y democrático de derecho la despenalización de esta conducta.

\section{¿Toda práctica eutanásica es relevante desde el punto de vista jurídico penal?}

La expresión eutanasia ha sido utilizada históricamente para significar conductas de la más variada naturaleza, con connotaciones filosóficas, éticas y jurídicas, también diversas.

Esta gran profusión de acepciones y clasificaciones reclama, como preámbulo necesario en el análisis de esta materia, la delimitación conceptual del término, con el objeto de determinar aquellas conductas eutanásicas cuya realización se encuentra penalmente tipificada.

Etimológicamente, la expresión eutanasia deriva del griego $e u$, bien y thánatos, muerte, pudiendo ser traducida como "buena muerte" o "muerte apropiada".

Como señala Luis Fernando Niño (1, p.81):

al paso de los siglos, no obstante, este conciso sentido terminológico, se fue tornando más y más difuso, traduciéndose en 'muerte rápida y sin tormentos', 'muerte digna, honesta y con gloria', y hasta 'bella muerte', pasando por 'muerte tranquila y fácil' y 'muerte misericordiosa' o 'piadosa', por nombrar sólo algunos de los significados que se le prodigaron.

El Diccionario de la Real Academia Española de la Lengua, da dos acepciones de esta palabra, definiéndola como "muerte sin sufrimiento fisico" y como "acortamiento voluntario de la vida de quien sufre una enfermedad incurable, para poner fin a sus sufrimientos"(2).

La primera de las acepciones transcritas se corresponde con el significado etimológico del término y tiene un alcance genérico, pues comprende todas aquellas situaciones en las cuales se produce la muerte sin padecimientos, sea que ésta sobrevenga por causas naturales o bien como consecuencia de conductas -activas u omisivastendientes a acelerar la muerte del enfermo terminal, en ambos casos con o sin intervención de terceros. Dada la enorme latitud de esta acepción, es menester delimitar el concepto, restringiéndolo a aquellas acciones $u$ omisiones cuya realización puede ser considerada relevante desde el punto de vista del ius puniendi. 
Hechas estas precisiones, salta a la vista la necesidad de excluir del concepto de eutanasia aquellas conductas tendientes a paliar los padecimientos del paciente, sin influir en el desarrollo natural del proceso de muerte (eutanasia natural). Se trata de acciones irrelevantes para el derecho penal y constituyen, por el contrario, verdaderos deberes morales y jurídicos. Igualmente debemos excluir de este concepto la provocación de la propia muerte, conducta que es igualmente ajena a cualquier tratamiento jurídico-penal ${ }^{\mathrm{i}}$.

La expresión queda reservada, en consecuencia, a aquellas conductas, realizadas por terceros, que tienen por objeto acortar la vida del moribundo, sentido que aparece recogido por la segunda acepción proporcionada por el Diccionario de la Lengua Española.

Sin embargo, es necesario realizar otra precisión: no toda conducta tendiente a acortar el ciclo vital, realizada con el fin de paliar el sufrimiento del moribundo, es éticamente reprochable y penalmente relevante.

Para esclarecer este punto, resulta ilustrativo echar mano a aquella distinción que, en cuanto al tipo de acción realizada, distingue entre eutanasia activa, eutanasia pasiva y eutanasia de doble efecto. En la primera categoría, se comprenden aquellas acciones tendientes a provocar la muerte sin sufrimiento del paciente; la eutanasia pasi$v a$ consiste en inhibirse de actuar o abandonar un tratamiento ya iniciado, evitando interferir en un proceso causal de consecuencias letales; por último, estamos en presencia de una eutanasia de doble efecto cuando se acelera la muerte como consecuencia indirecta de acciones médicas que son ejecutadas con el fin de aliviar el sufrimiento de un paciente terminal (3).

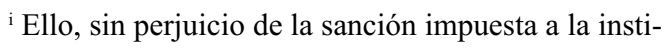
gación, auxilio o asistencia al suicidio y al suicidio ejecutivo. Sobre el particular, vid. (1, p.82-83).
}

La utilización de la expresión eutanasia para referirse a situaciones tan disímiles desde el punto de vista ético, puede llevar a equívocos. Respecto a la llamada eutanasia pasiva, es menester hacer una precisión: una cosa es provocar la muerte mediante la omisión deliberada de un cuidado debido, necesario y con sentido, y otra cosa es la omisión responsable de un cuidado extraordinario, no debido, no necesario y sin sentido. Algunos utilizan la expresión eutanasia pasiva para referirse a ambas situaciones; otros en cambio, sólo la emplean en la segunda acepción, utilizando la expresión adistanasia o antidistanasia para referirse al retiro de medios artificiales de reanimación, desproporcionados al caso (1, p.17). Se utiliza, asimismo, la expresión ortotanasia -entendida como muerte digna o debida a toda persona, vocablo confundido frecuentemente con adistanasia y aun con eutanasia pasiva- opuesta tanto a la distanasiai desproporcionada, como a la eutanasia homicida. Sin embargo, la expresión ortotanasia es omnicomprensiva, identificándose, prácticamente, con la eutanasia en su acepción etimológica, excluyendo sólo aquellas conductas que podríamos calificar de prácticas eutanásicas homicidas (1, p.86).

Dada la connotación valórica que la expresión eutanasia tiene en el lenguaje común, es conveniente no llamar eutanasia a la omisión o supresión de medios extraordinarios o desproporcionados (adistanasia) (4, p.126-127).

Excluimos, asimismo, la llamada eutanasia de doble efecto, por cuanto constituye una situación irreprochable desde el punto de vista ético e irrelevante en el ámbito punitivo $^{\text {iii }}$. Se excluye también la llamada eutanasia eugenésica, que consiste en la eliminación de los deficientes para evitar la transmisión genética de su deficiencia men-

\footnotetext{
ii Niño (1, p. 85), señala que la distanasia “consiste en prolongar la vida vegetativa de un individuo, echando mano, para ello, de los medios extraordinarios de reanimación con que hoy cuenta la ciencia médica".
} 
tal, y la eutanasia económica, que consiste en la eliminación de los que suponen una carga para la sociedad al no reportar utilidad alguna. Compartimos plenamente lo señalado por Barrenechea, en el sentido que ambos conceptos:

responden al principio insostenible del reconocimiento de la existencia de criaturas sin valor vital, condición que se determina por los mismos que deciden su eliminación (5, p.88-89).

Tanto la eutanasia eugenésica como la económica consisten en homicidios calificados cuya real entidad pretende encubrirse con un eufemismo (1, p.84-85).

\section{Elementos determinantes de la eutanasia desde el punto de vista penal: paciente terminal, móvil pietístico y consentimien- to del afectado}

Aquellas legislaciones que tipifican expresamente las prácticas eutanásicas, suelen establecer, en general, tres elementos determinantes en este tipo penal: debe tratarse de un paciente terminal o de un enfermo que sufre graves y dolorosos padecimientos, el sujeto activo debe actuar impulsado por un móvil pietístico y el sujeto pasivo debe manifestar su voluntad al respecto (consentimiento).

Resulta complejo precisar apriorísti- iii Así, la Iglesia Católica acepta plenamente este tipo de conductas. A este respecto, Pío XII señaló en 1957, en un discurso pronunciado ante un grupo internacional de médicos, que es aceptable la utilización de drogas destinadas a suprimir el dolor, a pesar de tener como efecto secundario abreviar la vida: "si entre la narcosis y el acortamiento de la vida no existe nexo causal alguno directo, puesto por la voluntad de los interesados o por la naturaleza de las cosas... y, si por el contrario, la administración de narcóticos produjese por sí misma dos efectos distintos, por una parte, el alivio de los dolores y, por otra, la abreviación de la vida, entonces es lícita”. La Iglesia Católica acepta la llamada eutanasia de doble efecto o activa indirecta, es decir, admite la administración de calmantes con el objeto de disminuir el sufrimiento de un paciente, a pesar de que, como efecto secundario, pueda acelerar la muerte del enfermo.

En 1980, la Sagrada Congregación para la Doctrina de la Fe emitió una Declaración sobre la eutanasia, en la cual condena la eutanasia activa directa, acepta la administración de drogas tendientes a aminorar el sufrimiento del paciente, aún cuando pueda, indirectamente, provocar o acelerar la muerte del enfermo y condena el encarnizamiento o ensañamiento terapéutico. Esta Declaración, por otra parte, abandona la criticada distinción entre medios ordinarios y extraordinarios, reemplazándola por la de medios proporcionados y desproporcionados, aceptando, además, la interrupción de los medios desproporcionados, cuando los resultados defrauden las expectativas puestas en ellos.

Más recientemente (1995), la Encíclica Evangelium Vitae de Juan Pablo II, confirma la posición históricamente sostenida por la Iglesia Católica, señalando que "la eutanasia es una grave violación de la Ley de Dios, en cuanto eliminación deliberada y moralmente inaceptable de una persona humana", reiterando las conclusiones ya manifestadas en la Declaración preparada por la Sagrada Congregación para la Doctrina de la Fe. Señala que la eutanasia debe distinguirse de la decisión de renunciar al llamado encarnizamiento o ensañamiento terapéutico, que son “ciertas intervenciones médicas ya no adecuadas a la situación real del enfermo, por ser desproporcionadas a los resultados que se podrían esperar o, bien, por ser demasiado gravosas para él o su familia. En estas situaciones, cuando la muerte se prevé inminente e inevitable, se puede en conciencia renunciar a unos tratamientos que procurarían únicamente una prolongación precaria y penosa de la existencia, sin interrumpir sin embargo las curas normales debidas al enfermo en casos similares". 
camente el concepto de paciente o enfermo terminal. Hay quienes han pretendido, incluso, fijar plazos (de horas, días y meses) dentro de los cuales ha de producirse la muerte. En nuestra opinión, esta cuestión debe ser resuelta caso a caso y, a lo más, pueden fijarse ciertas directrices generales. Por de pronto, nos contentamos con señalar, como hiciera Niño $(1$, p.98) y siguientes, hace ya más de un lustro, que:

sólo cuadrará hablar de eutanasia cuando la muerte fuere un acontecimiento próximo, sea por causa de una enfermedad grave o de dolencias irreversibles de la vejez o de daños accidentales, en el cuerpo o en la salud, de pronóstico letal.

Lo que sí debe existir es certeza -en la medida de lo posible- en cuanto al carácter terminal del enfermo, de acuerdo a los medios técnicos disponibles.

Sin embargo, muchas de las legislaciones que se ocupan del tema no se limitan a exigir la calidad de enfermo terminal, sino que hacen extensivo el tipo de homicidio eutanásico respecto de pacientes que sufren graves padecimientos o lesiones, aunque no exista inminencia de la muerte. Creemos que estas dos situaciones deben permanecer perfectamente diferenciadas desde el punto de vista conceptual y jurídico. Independientemente de la consideración legislativa, preferimos reservar la expresión eutanasia para aquellos casos de "reducción anticipada del curso de la muerte" y no para la abreviación inicua del curso de la vida (1, p.99). La simple aceptación de la causa de sufrimiento, no acompañada del estado de paciente terminal, no constituye verdadera eutanasia ${ }^{\text {iv }}$.

\footnotetext{
${ }^{\text {iv }}$ Así, v.gr., el caso de Howard Andrews, condenado por uxoricidio a 15 años de cárcel y cuadrapléjico, a raíz de un intento de suicidio, pero sin riesgo de vida, quien expresó su negativa a ser nutrido y medicado, situación que fue convalidada por la Corte Suprema de California (EE.UU.). Vid. (1, p.94-95).
}

En cuanto a los móviles de piedad que deben impulsar al sujeto activo en su actuación, se trata de un elemento subjetivo del tipo que -unido a los demás requisitosjustifica la atenuación de la pena, en relación con los tipos de homicidio simple y agravado. La Corte Constitucional de Colombia, en sentencia número C-239/97, ha señalado que:

quien mata a otro por piedad, con el propósito de ponerles fin a los intensos sufrimientos que padece, obra con un claro sentido altruista, y es esa motivación la que ha llevado al legislador a crear un tipo autónomo, al cual atribuye una pena considerablemente menor a la prevista para el delito de homicidio simple o agravado (6, p.15).

Finalmente, el consentimiento del paciente también es un elemento indispensable para que estemos en presencia de una conducta eutanásica, pues el sujeto activo siempre debe obrar en el interés exclusivo del enfermo. La voluntad debe ser prestada por un sujeto plenamente capaz $y$, obviamente, no puede adolecer de vicios.

Ahora bien, ¿qué sucede cuando el paciente se encuentra imposibilitado de manifestar su voluntad? En estos casos suele recurrirse al proxy consent o al substituted judgement. Los que lo quieren y conocen deciden lo que redundará en su mejor interés y beneficio (4, p.141). Hay quienes sostienen que el proxy no debería en ningún caso realizar actos de eutanasia directa aunque tal fuere el deseo expresado anteriormente por el ahora incompetente (4, p.141). Algunas legislaciones exigen como elemento del tipo la manifestación de voluntad del sujeto pasivo en orden a poner fin a su sufrimiento; por lo tanto, de no concurrir su voluntad, la conducta eutanásica no quedaría comprendida en el tipo privilegiado de homicidio piadoso, debiendo ser subsumida en los tipos generales de homicidio. Otros 
ordenamientos jurídicos, en cambio, permiten subsumir la conducta en el tipo especial de homicidio piadoso, aún cuando el paciente no hubiese manifestado voluntad alguna al respecto. En nuestra opinión, la eutanasia practicada sobre un paciente que no ha manifestado su consentimiento es éticamente inaceptable.

\section{Concepto de eutanasia}

De lo expuesto en los párrafos precedentes podemos extraer una serie de consideraciones que nos permitirán delimitar conceptualmente las prácticas eutanásicas. Hemos señalado hasta la redundancia que la decisión de eliminar del concepto una serie de conductas tradicionalmente comprendidas en el término eutanasia, se debe a la necesidad de reservar esta expresión -por lo menos para los fines de este trabajo- exclusivamente para referirnos a aquellas acciones $u$ omisiones que pueden ser sancionadas penalmente, habida cuenta de la falta de regulación del fenómeno eutanásico que existe en el derecho comparado.

a) Las prácticas eutanásicas pueden consistir en una acción o en una omisión.

b) Se excluye de toda consideración punitiva la no aplicación de tratamientos desproporcionados y excepcionales, cuando es cierta la inminencia de la muerte, como, asimismo, la supresión de éstos (adistanasia). Para estos efec-

\footnotetext{
v A este respecto, resulta ilustrativo el conocido caso de Karen Ann Quinlan, de Nueva Jersey (EE.UU.), quien a raíz de la ingestión de una elevada dosis de alcohol y fármacos protagonizada durante una fiesta en que celebraba su emancipación, cayó en un irreversible estado de coma, en el que se mantuvo desde el 14 de abril de 1975 hasta el 12 de junio de 1985. Antes de un año, el máximo órgano judicial de Nueva Jersey autorizó su desconexión de los modernos aparatos de reani-
}

tos, la calidad de medio proporcionado/desproporcionado deberá determinarse teniendo en cuenta la situación concreta del enfermo y su "esperabilidad" de vida (1, p.191). Así, verbigracia, proceder al retiro de medios artificiales de reanimación será, atendiendo a las circunstancias particulares del caso, perfectamente lícito y ajustado a derecho, debiendo conservarse, exclusivamente, aquellos medios que sólo conservan hidratado y nutrido el cuerpo del paciente $^{\mathrm{v}}$.

c) Es lícito suministrar al paciente drogas y calmantes que tiendan a aminorar su sufrimiento, aunque esta conducta indirectamente acelere la muerte.

d) El sujeto pasivo debe ser -necesariamente- un paciente terminal. La acción u omisión debe ser siempre dirigida a eliminar su sufrimiento, causado por una enfermedad irreversible y dolorosa.

e) El paciente debe manifestar su consentimiento. Sin embargo, algunas legislaciones tipifican el homicidio piadoso, sin requerir la manifestación de voluntad del enfermo.

f) El sujeto activo debe obrar impulsado por un fin de piedad.

g) Por regla general, el médico que realiza alguna de las conductas contempladas en los puntos precedentes (b y c), obra dentro de la causal de justificación de "ejercicio legítimo de un derecho u oficio", no actuando, por ende, de manera antijurídica.

mación que complementaban el mantenimiento de sus funciones vitales. Pero la vida neurovegetativa de Karen Ann se mantuvo, nutrida e hidratada artificialmente, hasta superar el decenio; y -con ella- el renovado debate acerca de la cuestión eutanásica. Cuando su corazón, finalmente, se detuvo, Karen pesaba 30 kilos, estaba la mayor parte del tiempo en posición fetal y se mantenía totalmente inconsciente de lo que sucedía a su alrededor. Vid. (1 p.25-195-197). 
Delimitada la comprensión del término en análisis, podemos definir la eutanasia, en términos generales, como toda acción $u$ omisión de un cuidado debido, necesario y eficaz, tendiente a producir deliberadamente la muerte de un enfermo terminal, aquejado de graves padecimientos, y con el fin de eliminar su sufrimiento"vi . Sólo las acciones $u$ omisiones comprendidas en esta acepción pueden ser sancionadas penalmente. Ir más allá de estos límites implicaría vulnerar el principio de protección, frontera infranqueable en un Estado social de derecho.

\section{La eutanasia desde el punto de vista de su tipificación objetiva}

Precisado el concepto de eutanasia para los fines del presente capítulo, es atingente que nos preguntemos cómo recoge el ordenamiento jurídico penal -desde el punto de vista de la tipicidad objetiva-aquellas conductas que se enmarcan dentro de esta noción restringida de eutanasia.

La primera cuestión que salta a la vista es que las prácticas eutanásicas significan una forma de lesión del bien jurídico "vida". Estas prácticas, precisamente, ponen término a la existencia biológica del individuo; por consiguiente, es en esta categoría que debemos encontrar el tipo legal en el cual subsumir la eutanasia.

Tradicionalmente, se comprenden entre los delitos contra la vida las siguientes figuras: el homicidio, en sus diversas formas, el aborto, el auxilio al suicidio, la inducción o instigación al suicidio y el auxilio ejecutivo (homicidio-suicidio). Debemos excluir, desde ya, el aborto como posible figura típica, pues la eutanasia supone, necesariamente, la existencia de un individuo con vida

vi JUAN PABLO II, en la Encíclica Evangelium Vitae, define la eutanasia como "una acción o una omisión que por su naturaleza y en la intención causa la muerte, con el fin de eliminar cualquier dolor". Señala, en consecuencia, que "la eutanasia se sitúa, pues, en el nivel de las intenciones o de los métodos usados". humana independiente; es el nacimiento el hecho que separa las conductas abortistas de las homicidas ${ }^{\mathrm{vii}}$. Por consiguiente, desde el punto de vista de la tipicidad objetiva, la eutanasia constituye una forma de homicidio. También se excluyen el auxilio y la inducción al suicidio, pues, la primera de estas figuras, consiste en actos de cooperación al suicidio de una persona y, la segun$\mathrm{da}$, en la influencia directa y eficaz de un sujeto sobre otro para que se suicide $(5$, p. 90 91). En ninguna de estas dos situaciones es el tercero el que realiza la muerte de la persona, lo cual impide, absolutamente, poder considerar las prácticas eutanásicas como constitutivas de estos delitos. En cuanto al auxilio ejecutivo, se trata, precisamente, de la muerte causada por un tercero, a solicitud de la víctima; es, por ende, en este tipo penal que debemos subsumir la eutanasia, a menos que exista un tipo especial para esta conducta. No obstante, es del caso señalar que las legislaciones que tipifican el auxilio ejecutivo son las menos (v. gr., art. $312 \mathrm{del}$ Código Penal Federal de México).

Ahora bien, tradicionalmente las legislaciones contemplan diversas figuras de homicidio. Básicamente, se suele distinguir entre homicidio simple, homicidio agravado o calificado e infanticidio. Diversos ordenamientos jurídicos contemplan, además, una figura específica para la eutanasia, bajo la forma del llamado homicidio pietístico $^{\text {viii }}$. En estos casos la discusión jurídico penal no presenta mayores dificultades, por lo menos desde el punto de vista de su configuración típica, pues son estas disposiciones -especiales- las que deben aplicarse a las prácticas eutanásicas. El problema se plantea en aquellas legislaciones que han guardado silencio frente a la realización de

\footnotetext{
vii Sin perjuicio de la existencia del aborto eutanásico.

viii V.gr., Bolivia, art. 257 CP.; Colombia, art. 326 CP.; El Salvador, art. 130 CP.; Paraguay, art. 106 CP.; Perú, art. 212 CP.
} 
conductas eutanásicas; la solución debe buscarse, en consecuencia, en los tipos generales de homicidio. Cabe preguntarse, entonces, cuál de todas las figuras de homicidio es aplicable a estas prácticas.

Una primera aproximación nos lleva a concluir, desde luego, que se excluye toda forma de homicidio culposo, pues la eutanasia es incompatible con la idea de negligencia o descuido: se trata, por ende, de una forma de homicidio doloso ${ }^{\text {ix }}$.

Debemos eliminar, asimismo, la figura del infanticidio como tipo penal en el cual subsumir las prácticas eutanásicas. En efecto, esta figura establece, generalmente, una pena disminuida para aquellas personas -normalmente la madre y ciertos parientesque dan muerte a un recién nacido, con el objeto de ocultar una deshonra. Esta motivación es incompatible con los móviles pietísticos y con el exclusivo interés del enfermo que están envueltos en la eutanasia.

En cuanto al homicidio calificado o asesinato, nos interesan particularmente dos circunstancias que las legislaciones, tradicionalmente, suelen incluir como casos de agravación de la pena: el uso de veneno u otro medio insidioso y la premeditación. Podría pensarse que la eutanasia activa realizada, verbigracia, mediante una inyección letal, constituiría un asesinato mediante la utilización de veneno. Por otra parte, la premeditación conocida podría aplicarse tanto a la eutanasia activa como omisiva. Debe-

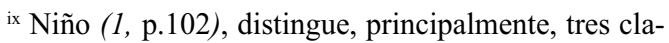
ses de eutanasia (que él llama resolutiva): activa directa, activa indirecta y pasiva. Desde el punto de vista volitivo, el primer caso se sitúa en el ámbito del dolo directo de primer grado; la denominada eutanasia resolutiva activa indirecta -que equivale a la que hemos denominado eutanasia de doble efecto- correspondería a una situación de tipicidad activa dolosa indirecta o de segundo grado o de consecuencias necesarias, sin descartar que, en ciertas situaciones, pudiera mantenerse en el grado volitivo inferior del dolo eventual; y la eutanasia pasiva, entraría de lleno en el ámbito de
}

mos descartar, sin embargo, estas posibilidades. El homicidio agravado contempla situaciones que revelan una especial maldad por parte del autor, lo cual no se condice con los móviles de piedad y el interés del moribundo que están presentes en la eutanasia. Prueba suficiente de ello es la pena disminuida que para el homicidio pietístico contemplan las legislaciones que se han hecho cargo de estos casos.

El parricidio, por las mismas consideraciones anteriores, debe ser descartado como figura típica posible, pues no es más que una forma agravada de homicidio, en razón de los vínculos de parentesco que ligan a víctima y victimario. Incluir las prácticas eutanásicas en cualquier forma de homicidio agravado atenta derechamente contra el principio de culpabilidad.

La conclusión evidente es, entonces, la siguiente: en aquellas legislaciones que no contemplan el tipo de homicidio pietístico ni de auxilio ejecutivo al suicidio, las prácticas eutanásicas sólo pueden ser subsumidas en el tipo penal de homicidio simple ${ }^{\mathrm{x}}$. No obstante ello, esta solución es absolutamente insatisfactoria, pues, las penas señaladas para estos casos, son elevadas y bien sabemos que en un Estado de derecho debe existir proporcionalidad entre las penas aplicables y el grado de culpabilidad del actor.

El homicidio por piedad constituye una forma de homicidio atenuado por el motivo del autor y por el pedido de la víctima. No

la tipicidad dolosa omisiva impropia o de comisión por omisión. Compartiendo las apreciaciones de este autor, debemos reiterar lo ya señalado, en orden a excluir del concepto de eutanasia la llamada de doble efecto, pues, sin perjuicio de las consideraciones en cuanto al dolo, constituye, por lo menos, una conducta ajustada a derecho, amparada por la causal de justificación de "ejercicio legítimo de un derecho u oficio".

x V.gr., Argentina, art. 79 CP.; Brasil, art. 123 CP.; Chile, art. 391 núm. $2^{\circ}$ CP.; Ecuador, art. 449 CP.; Guatemala, artículos 123 y 124 CP.; Honduras, art. 116 CP.; Venezuela, art. $407 \mathrm{CP}$. 
hace primar la piedad y el carácter insoportable del dolor sobre la incolumidad de la vida $y$, por consiguiente, no justifica el hecho. Tampoco acepta la exoneración de castigo, ni admite sólo que la pena se atenúe excepcional o facultativamente. Se limita a seguir la tesis que atenúa la imputación homicida. Se diferencia del homicidio simplemente consentido o del homicidio a pedido de la víctima ${ }^{\mathrm{xi}}$, porque el móvil de piedad del autor es esencial (7, p.150-151).

\section{Ordenamientos jurídicos que tipifican expresamente el homicidio por piedad}

El tratamiento legislativo de la eutanasia en los ordenamientos jurídicos latinoamericanos es bastante heterogéneo. La tendencia general es la de considerar las prácticas eutanásicas como delito. Las diferencias se producen al momento de la regulación típica de estas prácticas. Básicamente, podemos distinguir dos grupos de países: aquellos que tipifican especialmente las prácticas eutanásicas y aquellos que guardan silencio al respecto, siendo aplicables, en consecuencia, las disposiciones generales relativas al homicidio. Cabe destacar que la sanción es considerablemente menor en el primer caso. A continuación, nos referiremos a algunas legislaciones que contienen tipos especiales de homicidio por piedad:

a) La legislación punitiva de Bolivia, es de aquéllas que ha introducido en su ordenamiento jurídico un tipo penal que se refiere expresamente a la eutanasia. En efecto, el art. 257 CP. dispone:

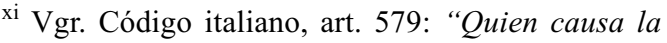
muerte de un hombre con su consentimiento... "; Código alemán, § 216: "Si alguien ha sido determinado al homicidio por el pedido expreso y serio de la víctima, se impondrá prisión no inferior a tres años".
}

Homicidio piadoso. Se impondrá la pena de reclusión de uno a tres años, si para el homicidio fueren determinantes los móviles piadosos y apremiantes las instancias del interesado, con el fin de acelerar una muerte inminente o de poner fin a graves padecimientos o lesiones corporales probablemente incurables, pudiendo aplicarse la regla del artículo 39 y aún concederse excepcionalmente el perdón judicial.

El art. 39, por su parte, dispone:

Atenuantes especiales. En los casos en que este Código dispone expresamente una atenuación especial, se procederá de la siguiente manera:

1) La pena de presidio será substituida por la de reclusión.

2) La de reclusión, por la de prestación de trabajo.

3) En los demás casos, la escala será disminuida de una tercera parte a la mitad, sin que en ningún caso la pena pueda ser inferior al mínimo legal.

Es del caso, asimismo, traer a colación el art. 64 CP., que se refiere, precisamente, al perdón judicial, posibilidad contemplada por el tipo de "homicidio piadoso":

Perdón judicial. El juez podrá conceder, excepcionalmente, el perdón judicial al autor de un primer delito cuya sanción no sea mayor a un año, cuando por la levedad especial del hecho y los motivos determinantes, existan muchas probabilidades de que no volverá a delinquir.

La concesión de perdón judicial está contemplada dentro de las disposiciones generales y es aplicable a todo delito que reúne los requisitos establecidos por el art. 64 . 
La conducta continúa siendo antijurídica, pero, dadas las circunstancias particulares del caso, se establece una pena bastante más reducida que la indicada para el homicidio simple o agravado. Establece, eso sí, una serie de requisitos para que la conducta pueda ser catalogada como homicidio pietístico. Cobran especial importancia los móviles que han llevado al autor a la realización de tal conducta. Se requiere, precisamente, que el homicida obre movido por piedad, elemento subjetivo del tipo que excluye cualquier otro móvil en la comisión de este delito. Quien mata movido por un interés distinto (v.gr. económico o eugenésico), no será sancionado conforme a esta disposición, sino que de acuerdo con las otras formas de homicidio contempladas en el código punitivo boliviano. Además, se requiere la concurrencia de ciertas condiciones objetivas en el sujeto pasivo, que pueden ser "un estado de muerte inminente" o el hecho de estar afecto a "graves padecimientos o lesiones corporales probablemente incurables".

El tipo exige, por otro lado, que el sujeto activo obre en virtud de "instancias apremiantes del interesado", lo cual deja en evidencia que, para que estemos en presencia de un homicidio pietístico, es menester el consentimiento del interesado, y la falta de éste será causal de atipicidad de la conducta, en lo que a este tipo penal se refiere, pudiendo ser constitutiva de alguna de las otras formas de homicidio que la ley contempla.

b) Colombia regula el homicidio pietístico en el art. 326 CP., que dispone:

Homicidio por piedad. El que matare a otro por piedad, para poner fin a intensos sufrimientos provenientes de lesión corporal o enfermedad grave e incurable, incurrirá en prisión de seis (6) meses a tres (3) años.
Al igual que en el caso anterior, los elementos a que este tipo hace referencia son los móviles pietísticos y los intensos sufrimientos provenientes de lesión corporal o enfermedad grave e incurable. No se exige la manifestación de voluntad del sujeto pasivo para la configuración de este delito.

La Corte Constitucional de Colombia, en sentencia de 20 de mayo de 1997, pronunciada a propósito del ejercicio de la acción pública de inconstitucionalidad, deducida en contra del art. 326 CP., declaró la exequibilidad de dicha norma, con el agregado $-\mathrm{y}$ he aquí la enorme relevancia de esta sentencia- que:

en el caso de los enfermos terminales en que concurra la voluntad libre del sujeto pasivo del acto, no podrá derivarse responsabilidad para el médico autor, pues la conducta está justificada (6, p.24).

Es decir, se sanciona la eutanasia sólo cuando no concurre la voluntad del enfermo, siempre que se cumplan los otros requisitos. Añade el tribunal en la parte resolutiva de esta sentencia una exhortación al Congreso colombiano:

para que en el tiempo más breve posible, y conforme a los principios constitucionales y a elementales consideraciones de humanidad, regule el tema de la muerte digna (6, p.25).

La Corte, en esta misma sentencia, señala algunos puntos que considera esenciales en una futura regulación legal de esta materia (6, p.24):

- Verificación rigurosa, por personas competentes, de la situación real del paciente, de la enfermedad que padece, de la madurez de su juicio y de la voluntad inequívoca de morir. 
- Indicación clara de las personas (sujetos calificados) que deben intervenir en el proceso.

- Circunstancias bajo las cuales debe manifestar su consentimiento la persona que consiente en su muerte o solicita que se ponga término a su sufrimiento: forma como debe expresarlo, sujetos ante quienes debe expresarlo, verificación de su sano juicio por un profesional competente, etc.

- Medidas que deben ser usadas por el sujeto calificado para obtener resultado filantrópico.

- Incorporación al proceso educativo de temas como el valor de la vida y su relación con la responsabilidad social, la libertad y la autonomía de la persona, de tal manera que la regulación penal aparezca como la última instancia en un proceso que puede converger en otras soluciones.

Como estas regulaciones sólo pueden ser establecidas por el legislador, la Corte considera que mientras se regula el tema, en principio, todo homicidio por piedad de enfermos terminales debe dar lugar a la correspondiente investigación penal, a fin de que en ella, los funcionarios judiciales, tomando en consideración todos los aspectos relevantes para la determinación de la autenticidad y fiabilidad del consentimiento, establezcan si la conducta del médico ha sido o no antijurídica, en los términos señalados en esta sentencia.

La trascendencia de este fallo salta a la vista. Hoy por hoy, de conformidad con la interpretación de la Corte Constitucional, la eutanasia realizada con la voluntad libre del moribundo no acarrea responsabilidad para el médico que la practica, es decir, el consentimiento es causa de justificación de la muerte producida en este caso específico. c) En El Salvador, la eutanasia queda comprendida en el art. 130, bajo la forma de homicidio piadoso:

El homicidio causado por móviles de piedad, con el fin de acelerar una muerte inminente o poner fin a graves padecimientos, será sancionado con prisión de uno a cinco años siempre que concurran los requisitos siguientes:

1) Que la víctima se encontrare en un estado de desesperación por sufrimientos observables, que fueren conocidos públicamente y que la opinión de los médicos que la asistan asi lo hubiere manifestado;

2) Que el sujeto activo estuviere ligado por algún vínculo familiar, amistad intima $o$ de amor con el enfermo; $y$,

3) Que el sujeto pasivo demostrare su deseo de morir por manifestaciones externas de ruegos reiterados y expresos.

La legislación salvadoreña, además de los móviles de piedad, la condición de paciente terminal o enfermo con graves padecimientos y la manifestación de voluntad del interesado (número $3^{\circ}$ ), establece otras exigencias, señaladas en los numerales $2^{\circ}$ y $3^{\circ}$. Cabe destacar entre estos requisitos, la referencia a la opinión de facultativos (número $1^{\circ}$ ) y la especial condición que debe concurrir en el sujeto activo, quien debe estar unido al afectado por especiales vínculos (número $2^{\circ}$ ).

d) El Código Penal de Paraguay, también regula expresamente la eutanasia. E1 art. 106 prescribe:

Homicidio motivado por súplica de la víctima. El que matara a otro que se hallase gravemente enfermo o herido, obedeciendo a súplicas serias, reiteradas e insistentes de la víctima, será castigado con pena privativa de libertad de hasta tres años. 
e) Finalmente, la legislación de Perú establece en el art. 212:

Homicidio piadoso. El que, por piedad, mata a un enfermo incurable que le solicita de manera expresa y consciente para poner fin a sus intolerables dolores, será reprimido con pena privativa de libertad no mayor de tres años.

\section{Eutanasia y dignidad de la persona hu- mana}

Delimitado el concepto jurídico-penal de eutanasia, en los términos restrictivos expuestos anteriormente, cabe preguntarse acerca de la "eticidad" de una posible legislación eutanásica; en otras palabras, si es aceptable, desde el punto de vista ético y jurídico, despenalizar este tipo de conductas.

Los defensores de la despenalización de la eutanasia fundamentan sus razonamientos, precisamente, en la "dignidad de la persona humana". Según hemos señalado más arriba, suele identificarse la expresión eutanasia con "muerte digna". El término dignidad, que ha sido utilizado de manera creciente en diversos cuerpos normativos nacionales e internacionales ${ }^{\mathrm{xii}}$, es de compleja definición y en nombre de la "dignidad de la persona humana", se han defendi-

\footnotetext{
xii Así, v.gr., el preámbulo de la Declaración Universal de Derechos Humanos, remite al reconocimiento de la "dignidad intrínseca y de los derechos iguales e inalienables de todos los miembros de la familia humana", como base de la libertad, la justicia y la paz en el mundo. El Pacto Internacional de Derechos Civiles y Políticos, inicia su preámbulo reconociendo "la dignidad inherente a todos los miembros de la familia humana", señalando, más adelante, que los derechos iguales e inalienables del hombre se derivan de esa misma dignidad. La "Convention for the Protection of Human Rights and Dignity of the Human Being with regard to the Application of Biology and Medicine: Convention on Human Rights and Biomedicine",
}

do procedimientos, especialmente en el campo de la salud, muy cuestionados desde un punto de vista ético $(8$, p.3).

De la dignidad inherente a la persona humana derivan todos los derechos humanos, comprendido, obviamente, aquel derecho primigenio a la vida. Respetar la dignidad del individuo implica, necesariamente, abstenerse de realizar cualquier acto, incluida la promulgación de normas, que puedan menoscabarla (1, p.123-124).

Pero, ¿qué debemos entender por "dignidad"? Los hombres tienen dignidad por el solo hecho de ser tales, razón por la cual debemos descartar, desde luego, cualquier acepción que pretenda relativizar este concepto ${ }^{\text {xiii }}$. Desde esta perspectiva "ontológica", la dignidad de la persona humana es absoluta, existe independientemente de su situación social, política, religiosa, etc., y no es modificable bajo ninguna circunstancia. Depende de su "ser y no de su "hacer" (8, p.3). En palabras de Kant (10, p.319):

el deber de respetar a mi prójimo está contenido en la máxima de no degradar a ningún otro hombre convirtiéndole únicamente en medio para mis fines (no exigir que el otro deba rebajarse a sí mismo para entregarse a mi fin).

El hombre es un fin en sí mismo y nunca ha de ser tratado como un medio o instru-

del Consejo de Europa, señala también en su preámbulo que "the misuse of biology and medicine may lead to acts endangering human dignity...".

xiii Así, por ejemplo, Hobbes (9), 1997, señala que "la valía pública de un hombre, que es el valor que le ha sido asignado por la república, es lo que comúnmente llamamos DIGNIDAD. Y ese valor que le ha sido dado por la república se manifiesta en puestos de mando, en responsabilidades judiciales, en empleos públicos, o mediante nombres y títulos que se usan para dar distinción a ese valor". No es, pues, en este sentido que entendemos la expresión dignidad. 
mento. En otros términos, significa que el ser humano no se puede vender ni comprar, que su vida es un fin en sí mismo y que toda la ciencia y las artes tienen que ir orientadas al servicio de este fin que es la persona humana, de otra forma se vulnera su dignidad $\mathrm{y}$ entonces el ser humano recibe un trato indigno (8, p.3).

El ser humano, dotado de dignidad, ¿puede disponer de su vida? Desde una perspectiva "autonomista", suele responderse de manera afirmativa. A este respecto, se señala que la dignidad de la persona humana deriva, precisamente, de la libertad, la cual debe ser respetada incluso en caso de autodestrucción. La dignidad -así considerada- no sería, en consecuencia, un principio de carácter absoluto, sino que dependería del ejercicio de la libertad. Ello significa que los incapaces absolutos -v.gr., un demente- $\mathrm{o}$ aquellos que se encuentran privados de su libertad por razones legales, han perdido su dignidad. En nuestra opinión, la situación es, precisamente, la contraria: la libertad deriva de la dignidad de la persona humana; se respeta la libertad porque se tiene dignidad, y no al revés.

Siendo la dignidad humana de carácter

${ }^{\text {xiv }}$ Interesante resulta a este respecto el parecer emitido por el Comitato Nazionale per la Bioetica, de Italia, de 14 de julio de 1995, sobre "Questioni bioetiche relative alla fine della vita umana". Este organismo llega a la conclusión de que ninguna legislación propiamente eutanásica puede tener valor bioético. Señala que es lícito y digno de respeto por parte del terapeuta el rechazo del paciente a someterse a una terapia, siempre que lo haga en forma libre, actual y consciente. Considera, asimismo, lícita cualquier intervención de carácter paliativo, siendo, además, un deber la suspensión por parte del médico de cualquier ensañamiento terapéutico. Por último -señala este Comité-, se considera ilícita cualquier forma de eutanasia eugenésica y sobre neonatos con malformaciones, como, asimismo, resulta gravemente ilícita cualquier forma de eutanasia realizada sobre un paciente que no ha prestado su consentimiento.

Por su parte, el Comité Consultif National d'Etique de Francia, en un parecer emitido con fecha 27 de enero de 2000 ( $\mathrm{N}^{\circ}$ 63: Avis sur fin de vie, arrêt de vie, euthanasie), señala acertadamente que la eutanasia propiamente dicha absoluto, ella no desaparece en caso de enfermedad terminal; incluso en el evento de que la persona en cuestión pida morir, hay que velar por su ser y por una atención máximamente cercana a su situación de sufrimiento.

En consecuencia, cualquier legislación que pretenda despenalizar la eutanasia homicida -entendida en los términos restrictivos enunciados en los párrafos precedentes- es inaceptable desde un punto de vista ético y jurídico. En efecto, la dignidad de la persona humana es un principio básico de cualquier Estado social y democrático de derecho y, por ende, es un principio que, necesariamente, debe inspirar todo el ordenamiento jurídico nacional. Cualquier disposición que lo vulnere debe reputarse, necesariamente, inconstitucional ${ }^{\mathrm{xiv}, \mathrm{xv}, \mathrm{xvi}}$.

\section{Referencias}

1. Niño L. Eutanasia. Morir con dignidad: consecuencias jurídico-penales. Buenos Aires: Editorial Universidad; 1994.

2. Diccionario de la Lengua Española. $21^{\mathrm{a}} \mathrm{ed}$. Madrid: Espasa Calpe; 1992.

3. Francisconi C, Goldim J. Tipos de Eutanásia.

no puede ser aislada del contexto más amplio representado por el hecho de morir, hoy en día, en un mundo fuertemente marcado por la técnica médica, con sus evidentes ventajas, pero también con sus limitaciones. El verdadero desafío frente al cual se encuentra colocada la sociedad-agrega este Comité- consiste en permitir a cada persona vivir su propia muerte de la mejor manera y, en lo posible, no ser desposeído de ella. Esto puede evitarse con una resuelta aplicación de los cuidados paliativos, con el acompañamiento de la persona hasta el final de su vida y con el rechazo al encarnizamiento terapéutico. Finalmente-concluye este organismo- ello permite reducir las peticiones de eutanasia a situaciones excepcionalísimas, las cuales podrían tener una traducción jurídica en la instauración de una $e x$ cepción de eutanasia. Sin embargo, provocar la muerte, cualquiera sean las circunstancias y las justificaciones, constituye siempre una transgresión. Si en una situación límite la decisión de detener la vida puede parecer un acto aceptable, tal decisión no podrá nunca convertirse en una práctica rutinaria o normal. 
[Serial On Line] 1997-98 [citado 2000 jul 27] Available from: URL: www.hcpa.ufrgs.br/gppg/ eutantip.htm

4. Masía J. ¿Eutanasia o buena muerte? Cuestiones éticas más allá y más acá de la muerte. $D i$ lemas éticos de la medicina actual-4. 1990; 9:141

5. Barrenechea J. Aspectos legales de la eutanasia. Dilemas éticos de la medicina actual-4. 1990; 9: 90-1.

6. Sánchez F. La eutanasia. Santafé de Bogotá, D.C.:Giro Editores Ltda.; 1997.

xv La World Medical Association, en la Declaración de Venecia de 1983, refiriéndose a las enfermedades terminales, señaló que el médico tiene el deber de tratar y, en la medida de lo posible, aliviar el sufrimiento del paciente, protegiendo siempre los intereses de éste, aún en el caso de enfermedades incurables. No obstante, el médico puede aliviar el sufrimiento de un paciente terminal, no aplicando un tratamiento, siempre que cuente con el consentimiento del paciente o de su familia, cuando no pueda expresar su voluntad. El médico, asimismo, debe abstenerse de emplear medidas extraordinarias, que no signifiquen beneficios para el paciente.

En la misma línea antes señalada, esta Asociación, en la Declaración de Madrid de 1987, concluyó que la eutanasia, entendida como el acto de terminar deliberadamente con
7. Núñez R. Tratado de Derecho Penal. Parte Especial. Delitos contra las personas. Vol. 3. Córdoba- Buenos Aires: Ediciones Lerner; 1977. p. 150-1.

8. Torralba F. Morir dignamente. Bioética \& Debat 1998; 12(2): 3.

9. Hobbes T. Leviatán. Traducción, prólogo y notas de Carlos Mellizo. Barcelona: Ediciones Altaya S.A.; 1997.

10. Kant I. La metafisica de las costumbres. Traducción y notas de Adela Cortina y Jesús Conill Sancho. Barcelona: Ediciones Altaya S.A.; 1997. la vida de un paciente, ya sea que la solicitud provenga de éste o de sus familiares próximos, es éticamente inadecuada. Esto no impide al médico respetar los deseos del paciente en orden a permitir el curso natural del proceso de muerte, en la fase terminal de una enfermedad.

${ }^{\text {xvi }}$ En relación con el rechazo de una terapia por parte del paciente: The Convention on Human Rights and Biomedicine, del Consejo de Europa, establece en el art. 5 lo siguiente: "An intervention in the health field may only be carried out after the person concerned has given free and informed consent to it. This person shall beforehand be given appropriate information as to the purpose and nature of the intervention as well as on its consequences and risks. The person concerned may freely withdraw consent at any time". 